\title{
Succussion
}

\section{A radical solution.}

\section{Steve Longworth}

We have just finished our retraining and now it's time to redeploy. Whoever would have thought it would come to this? We all started out with such high ideals. Well, except me of course. If I'm really honest, I only went into medicine because I thought it would be a great way for a rather ordinary looking bloke like me to meet lots of unattached, sexy young nurses who would then be sufficiently impressed by the title 'doctor' to form an orderly queue outside my bedroom door (and so it proved, I'm delighted to report). I guess that's why I've taken to this so easily. Ethics was never my strong suit. I'm really a rather cynical opportunist behind the carefully cultivated, charming, professional veneer.

Still, I'm apprehensive about our new role. I've never killed anyone before. Well, not intentionally (there was that rather unfortunate series of prescribing errors that the Trust swept under the carpet before hastily moving me on, but that's another story). Up to now, whenever I have stuck a knife into someone it was with their consent and under anaesthesia. This new role is going to take some getting used to, but I've always been open-minded. That's also why, despite the fierce scepticism and at times downright hostility of many of my colleagues, I was willing to use homeopathy. Let's face it, few other people were doing it and the general public are so gullible it meant that I could open up a nice little private practice and charge silly money for silly remedies with little competition.

You know the theory behind homeopathy? 'Like fights like'. So if you are treating a fever you give the patient something that causes a fever, but (and this is the important bit) you dilute it over and over again, and each time you dilute it the treatment gets stronger. With each dilution the solution is vigorously shaken, a process known as 'succussion'. There are those who speculate that succussion causes the water molecules to 'remember' the active ingredient even when Avogadro says there is not a trace of it left. Dilution makes it stronger. That's the part conventional science has the most trouble with, but there

are studies that show that homeopathic remedies do work, even in animals, so it can't all be the placebo effect despite the shaky theory. On the other hand I think that my bedside manner contributed just as much to the cures enjoyed by my pliant clientele as the elaborately prepared bottles of expensive water that I used to succuss. Success, suckers!

Perhaps we should have noticed sooner that something remarkable was happening. As life expectancy gradually rose throughout the early twentieth century we gave the credit to public-health reforms: clean water, efficient sewerage systems, the ending of unsanitary overcrowding and so on. When life expectancy continued to climb we pointed to our


is treated in a sewage farm and pumped offshore where it is diluted in the sea. The sea water evaporates to form clouds, with the water returning to earth as rain and collecting in reservoirs. We drink the water and the cycle starts all over again. Each step in the process involves a form of natural succussion. You see where this is going. With each dilution the original medicine gets stronger. Over 200 years every homeopathic remedy ever formulated has been diluted and blended over and over and over again, millions, maybe billions of times. At the end of the first decade of the twentyfirst century a critical dilution threshold was reached. Now any glass of water from any tap anywhere in the world is the most powerful all-purpose drug ever created. No more cancer, infection, inflammation, degeneration; everyone will now live for ever in perfect health, unless they are unlucky enough to suffer a sudden overwhelming physical injury. Immortality! What a disaster.

The world is rapidly overpopulating. There are simply not enough resources to go around. We may be immune to all known diseases and resistant to ageing but we still have to eat. House prices are stratospheric as every available space fills up. Water is the universal panacea and now universal panic's here. The world has been thoroughly shaken.

In India and the Far East, where population growth is the fastest, vast suicidal religious cults have emerged and

increasingly powerful pharmacopoeia so that by the start of the third millennium just about everyone over 60 was taking a statin to lower their cholesterol and often a bagful of other prescribed drugs as well. But when we all became, to all intents and purposes, immortal, there had to be a radical new explanation.

Think about this. Homeopathy has been around for 200 years, and over that period every homeopathic remedy that has ever been formulated has been taken on countless occasions by millions of people. The potency increases with each dilution. So when you drink a homeopathic medicine it gets diluted in your total body water, then you pee it out and flush the toilet, so it gets diluted in the sewerage system. The sewage are massively popular among the young and naive. Euthanasia for the Youth in Asia!

Here we have a solution based on our own massively popular mystical belief system - the National Lottery. Everyone has been allocated a unique set of numbers and the draw takes place twice weekly. It means we have been able to find important new work for all us unemployed doctors. We used to bring succour. Now no one wants a house call, but it's vital we force our way in, scalpel at the ready as we point the finger and proclaim the new Hypocritical Oath.

It's you!

Trust me, I'm a doctor.

Steve Longworth lives in Leicester, which was recently voted curry capital of Great Britain. 